\title{
Postoperative Malignant Hyperthermia Following Appendectomy
}

\section{Tomo Kakihara', Shin Sasaki ${ }^{1 *}$, Hiroshi Nakayama', Toshiyuki Watanabe', Hirotaka Oto $^{2}$, Keita Ichikawa² and Hirofumi Nakase ${ }^{3}$}

${ }^{1}$ Department of Surgery, Omori Red Cross Hospital, Tokyo, Japan

${ }^{2}$ Department of Anesthesiology, Omori Red Cross Hospital, Tokyo, Japan

${ }^{3}$ Department of Neurology, Omori Red Cross Hospital, Tokyo, Japan

Keywords: Malignant hyperthermia; Postoperative complication; Appendectomy

\section{Introduction}

Malignant Hyperthermia ( $\mathrm{MH})$ is a rare perioperative complication triggered by volatile anesthetic gases such as halothane, sevo flurane and the depolarizing muscle relaxant succinylcholine [1-3]. The pathophysiologic changes of $\mathrm{MH}$ are due to uncontrolled rise of myoplasmic calcium, which activates biochemical processes related to muscle activation $[4,5]$. The estimated incidence of $\mathrm{MH}$ is between 1:50000 and 1:150000 anesthesias [1]. Most of MH cases exhibits clinical symptoms during operations, and postoperative $\mathrm{MH}$ is uncommon [6,7]. The latency period between the anesthesia finish time and the onset of a sign indicative of $\mathrm{MH}$ is estimated in the range from 0 to $40 \mathrm{~min}$ [7]. The present report describes a case of $\mathrm{MH}$ which presented clinical symptoms around 4 hours after an emergent appendectomy, and was diagnosed as "almost certain" by The Clinical Grading Scale [8].

\section{Case Report}

A 40-year-old male was referred to Omori Red Cross hospital because of abdominal pain for several hours. His Body Mass Index (BMI) was $27.5 \mathrm{~kg} / \mathrm{m}^{2}(165 \mathrm{~cm}, 75 \mathrm{~kg})$. The pain localized in the right lower quadrant and there was diaphoresis and mandible thrill on arrival. Physical examination revealed tenderness on pressure in the right lower quadrant, but there was no muscular rigidity. He had a low grade fever of $37.3^{\circ} \mathrm{C}, 100$ beats/min, and $168 / 123$ blood pressure. He had suffered from hypertension and gastroesophageal reflux disease, but he had no history of neuromuscular disease and surgical operations. Also, he had no significant family history. He had been a heavy drinker and a smoker. Hematological examination revealed white blood cells 13500/ $\mathrm{mm}^{3}$, Glutamate Oxaloacetate Transaminase (GOT) $55 \mathrm{IU} / \mathrm{L}$, Glutamate Pyruvate Transaminase (GPT) $69 \mathrm{IU} / \mathrm{L}$, and $\gamma$-glutamyl transpeptidase ( $\gamma$-GTP) 449 IU/L. Other laboratory results were in normal range. A Computed Tomography (CT) scan demonstrated a

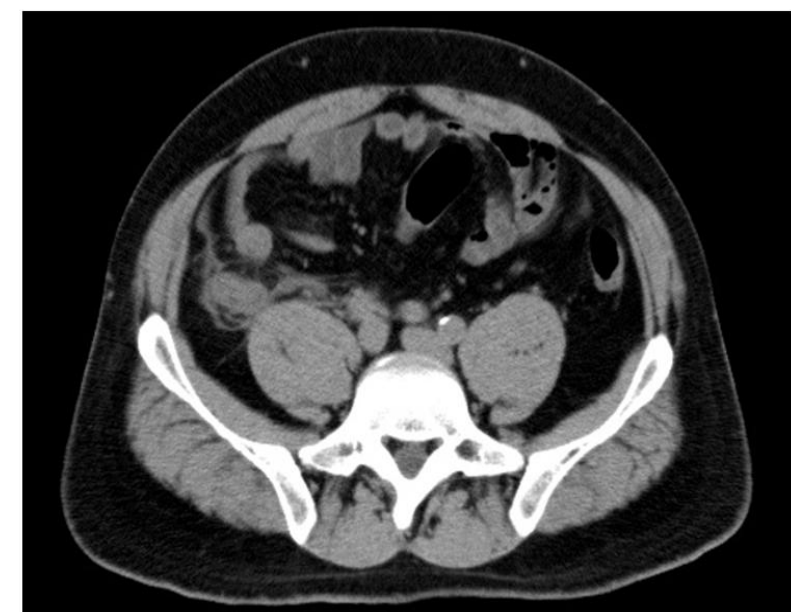

Figure 1: A Computed Tomography (CT) scan demonstrated a swelling of the appendix with elevated concentration of surrounding fat. swelling of the appendix with an elevated concentration of surrounding fat, making a diagnosis of acute appendicitis (Figure 1). Then, an emergent appendectomy was performed via pararectal incision. Anesthesia was induced with $200 \mathrm{mg}$ of propofol and sevoflurane, followed by $70 \mathrm{mg}$ of rocuronium bromide for endotracheal intubation. No abnormal muscular sign was observed during induction of anesthesia. Furthermore, during the operation, vital signs didn't change significantly, as shown in Figure 2. Body Temperature (BT) was stable around $39^{\circ} \mathrm{C}$. During the operation, droperidol, sugammadex sodium, lidocaine, flurbiprofen axetil were dosed. The anesthesia and operation times were 2 hours and 32 minutes, and 2 hours and 6 minutes, respectively. The blood loss was $38 \mathrm{~g}$, and the total infusion volume of Ringer's solution was $1700 \mathrm{ml}$. Urine output was $600 \mathrm{ml}$, and urine was clear with no abnormal findings. On arrival in the postoperative ward, the patient's blood pressure was $136 / 89 \mathrm{mmHg}$ with a pulse of 98 beats/ min, and his $\mathrm{BT}$ was $36.5^{\circ} \mathrm{C}$. No abnormal neuromuscular sign was seen. However, 4 hours after the operation, hyperthermia $\left(\mathrm{BT} 41.5^{\circ} \mathrm{C}\right)$, tachycardia (maximum HR was 190 beats/min), diaphoresis, muscular rigidity throughout the body, and disturbance of consciousness were suddenly emerged. Those symptoms faded out gradually. A brain CT scan showed normal image, and an abdominal CT scan showed abdominal incisional hernia probably due to extraordinary muscular rigidity. On the next day, hematological examination revealed that creatinine kinase (CK) (25764 IU/L, CK-MB was in normal range (8.0IU/L)), GOT (20817 IU/L), GPT (5054 IU/L), Lactate Dehydrogenase (LDH) (13110 IU/L), fibrin degradation products (FDP) $(101.9 \mathrm{mg} / \mathrm{dl})$, and CRP $(10.91 \mathrm{mg} / \mathrm{dl})$ were remarkably elevated, and that, on the contrary, platelet $(29000 / \mu \mathrm{l})$ and prothrombin percentage activity (31\%) were remarkably decreased. There was no abnormal blood gas analysis $(\mathrm{pH}$ 7.430, $\mathrm{PaO}_{2} 96.6 \mathrm{mmHg}, \mathrm{PaCO}_{2} 37.7 \mathrm{mmHg}$, Base excess $1.5 \mathrm{mmol} / \mathrm{L}$ ). The $\mathrm{MH}$ score defined by Larach was 53 and $\mathrm{MH}$ rank was 6, which means the qualitative likelihood was "almost certain". Furthermore, almost all symptoms and laboratory analysis of $\mathrm{MH}$ occurred. Hence, $\mathrm{MH}$ and Disseminated Intravascular Coagulation (DIC) were clinically diagnosed. We immediately started administration of dantrolene sodium and thrombo modulin. BT dropped gradually and hematological data got better day by day (Figure 3). Between 1 and 4 postoperative day, visual and auditory hallucination and monology revealed, and disappeared on the 5 postoperative day. There was no muscular symptom could be found during hospitalization after the appearance of muscular rigidity. Finally the patient was discharged on the 22 postoperative days. After 5 months from the initial operation,

*Corresponding author: Shin Sasaki, Department of Surgery, Omori Red Cross Hospital, 4-30-1 Chuo, Ota-ku, Tokyo 143-8527, Japan, Tel: +81-3-3775-3111; Fax: +81-3-3776-0004; E-mail: s-sasaki@omori.jrc.or.jp

Received January 31, 2014; Accepted February 17, 2014; Published February 28,2014

Citation: Kakihara T, Sasaki S, Nakayama H, Watanabe T, Oto H, et al. (2014) Postoperative Malignant Hyperthermia Following Appendectomy. Surgery Curr Res 4: 181. doi:10.4172/2161-1076.1000181

Copyright: (c) 2014 Kakihara T, et al. This is an open-access article distributed under the terms of the Creative Commons Attribution License, which permits unrestricted use, distribution, and reproduction in any medium, provided the original author and source are credited. 


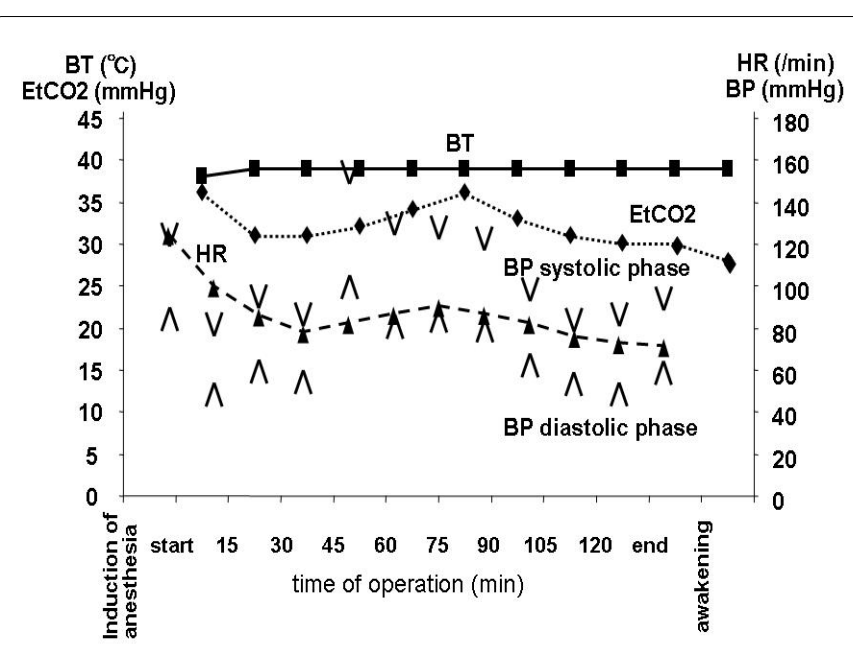

Figure 2: Vital signs during the operation. Body Temperature (BT), end-tidal carbon dioxide (ETCO2), Heart Rate (HR), and systolic and diastolic Body Pressure (BP) are shown.

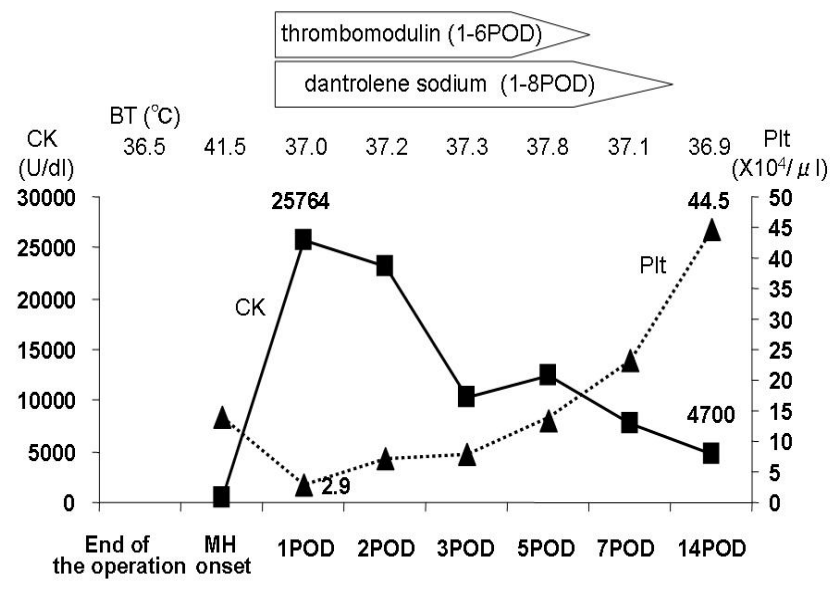

Figure 3: Postoperative change in body temperature (BT), creatinine kinase (CK), and platelet (PIt) are shown. Figures of their parameters got gradually better by the administration of thrombomodulin and dantrolene sodium.

abdominal incisional hernia repair was performed. At the same time, some portion of the rectus abdominis muscle was resected and applied for Calcium Induced Calcium Rate (CICR) test at the Saitama medical university. CICR test exhibited normal range.

\section{Discussion}

The incidence of $\mathrm{MH}$ is estimated between 1:50000 and 1:150000 anesthesia's [1]. Most of MH cases exhibits clinical symptoms during operations, and only few cases of postoperative $\mathrm{MH}$ have so far been reported [6,7], and their incidence was estimated about $1.9 \%$ among suspected $\mathrm{MH}$ cases. Although the diagnosis of $\mathrm{MH}$ is based on clinical presentation or laboratory analysis, the predisposition to $\mathrm{MH}$ has not been clear and we cannot preoperatively predict which patients are at risk of $\mathrm{MH}$. Inoperative management with prudent caution for $\mathrm{MH}$ is needed for early diagnosis of MH [9]. The Clinical Grading Scale was developed by Larach et al. in order to assist in clinical diagnosis [8]. This patient's MH score was 53 and MH rank was 6, which means the qualitative likelihood was "almost certain". Almost all symptoms and laboratory analysis of $\mathrm{MH}$ occurred in this case. In Japan, clinical diagnostic criterion drawn up by Morio et al. has been used to diagnose MH [10]. This criterion stresses to high grade fever during anesthesia or rapid elevation of body temperature, and our case was categorized into "postoperative abortive $\mathrm{MH}$ " In our case, the first clinical sign was tachycardia, and secondly hyperthermia, tachypnea, and rigidity. Whether an elevation of end-tidal carbon dioxide (ETCO2) concentration that is one of the principal diagnostic features of $\mathrm{MH}$ appeared or not was unclear. The variability in the order and time of onset of signs and no specific clinical sign of $\mathrm{MH}$ make the clinical diagnosis rather difficult, especially when the events are postoperatively occurred. The difficulties of diagnosis could make starting of appropriate treatment delayed, while the most important point of treatment is to start at early phase of $\mathrm{MH}$. Hence, we should not hesitate to start the treatment as soon as $\mathrm{MH}$ is suspected. Specific therapeutic drug for $\mathrm{MH}$ is dantrolene sodium which inhibits Sarcoplasmic Reticulum (SR) $\mathrm{Ca}^{2+}$ release [11].

$\mathrm{MH}$ is a hyper metabolic response to potent inhalation agents, the depolarizing muscle relaxant succinylcholine, and rarely, in humans, stresses such as vigorous exercise and heat. These triggers accelerate CICR system, and lead to uncontrolled release of intracellular calcium from skeletal muscle SR. The enhanced intracellular calcium results in activation of muscle contraction, oxygen consumption, carbon dioxide production, ATP breakdown and heat. In almost all cases, the MH susceptible patients have a defective calcium channel located in the SR membrane, termed the ryanodine receptor (RYR) [12]. The channel is closely associated with other proteins and structures, such as the di hydropyridine calcium channel that mediates transfer of voltage change to the RYR-1 receptor. Although mutations associated with MH susceptibility are found mainly in the gene for the RYR-1 [13,14], several mutations in other genes have so far reported. However, in most cases of $\mathrm{MH}$, responsible mutations have not been identified [12]. In this case, CICR test exhibited normal range, suggesting that mechanism of skeletal muscle calcium release might not be associated with RYR because this test reflects the function of $\mathrm{Ca}^{2+}$ homeostasis including RYR of SR in skeletal muscle. Other genes' mutations or polymorphisms could be associated with the onset of disease. Yuge and Mukaida performed CICR test for 43 patients with an episode of postoperative $\mathrm{MH}$, and CICR rate of 42 patients was in normal range [15]. This result supports our hypothesis, and suggests that the pathogenesis of postoperative $\mathrm{MH}$ might be different from that of classical $\mathrm{MH}$.

We used dantrolene sodium to treat the patient of postoperative $\mathrm{MH}$. The most important thing when we suspect that $\mathrm{MH}$ is occurred is to administer dantrolene sodium to the patient as soon as we can. Dantrolene sodium reduces fever production in skeletal muscle by directly interfering with muscle contraction through the inhibition of calcium-ion release from the SR [11]. In addition, dantrolene sodium has no life-limiting side effect that inhibits administrating.

Postoperative $\mathrm{MH}$ is a very rare complication, and its diagnosis from clinical presentation is very difficult. Actually, the mechanisms or clinical manifestations of MH have not been cleared, but MH could be one of life-threatening complications. We must keep in mind the possibility of $\mathrm{MH}$ onset even after any operation, and make immediately an appropriate treatment even for suspicious cases. And further accumulation of $\mathrm{MH}$ cases and more detailed molecular biological analysis are needed.

\section{Acknowledgement}

The authors thank Dr. Kikuchi $\mathrm{H}$ and Dr. Ichihara $\mathrm{Y}$ (Department of Anesthesiology, Saitama Medical University) for their valuable assistance and CICR test. 
Citation: Kakihara T, Sasaki S, Nakayama H, Watanabe T, Oto H, et al. (2014) Postoperative Malignant Hyperthermia Following Appendectomy. Surgery Curr Res 4: 181. doi:10.4172/2161-1076.1000181

\section{References}

1. Rosenberg H, Davis M, James D, Pollock N, Stowell K (2007) Malignant hyperthermia. Orphanet J Rare Dis 2: 21.

2. Hopkins PM (2000) Malignant hyperthermia: advances in clinical management and diagnosis. $\mathrm{Br} \mathrm{J}$ Anaesth 85: 118-128.

3. Stowell KM (2008) Malignant hyperthermia: a pharmacogenetic disorder. Pharmacogenomics 9: 1657-1672.

4. Balog EM, Fruen BR, Shomer NH, Louis CF (2001) Divergent effects of the malignant hyperthermia-susceptible $\operatorname{Arg}(615)-->C y s$ mutation on the $\mathrm{Ca}(2+)$ and $\mathrm{Mg}(2+)$ dependence of the RyR1. Biophys J 81: 2050-2058.

5. Yang T, Ta T, Pessah I, Allen $P$ (2003) Functional defects in six ryanodine receptor isoform-1 (RyR1) mutations associated with malignant hyperthermia and their impact on skeletal excitation-contraction coupling. J Biol Chem 278 : 25722-25730.

6. Inada H, Jinno S, Kohase H, Fukayama H, Umino M (2005) Postoperative hyperthermia of unknown origin treated with dantrolene sodium. Anesth Prog 52: 21-23.

7. Litman RS, Flood CD, Kaplan RF, Kim YL, Tobin JR (2008) Postoperative malignant hyperthermia: an analysis of cases from the North American Malignant Hyperthermia Registry. Anesthesiology 109: 825-829.
8. Larach MG, Localio AR, Allen GC, Denborough MA, Ellis FR, et al. (1994) A clinical grading scale to predict malignant hyperthermia susceptibility. Anesthesiology 80: 771-779.

9. Kim DC (2012) Malignant hyperthermia. Korean J Anesthesiol 63: 391-401.

10. Morio M (1992) Akuseikonetsusyo, neccyuusyo oyobi akuseisyokogun (in Japanese). Nihon Rinsyomasui Gakkaizasshi (J Jpn Soc Clin Anesth) 12: 1-16.

11. Zhao F, Li P, Chen SR, Louis CF, Fruen BR (2001) Dantrolene inhibition of ryanodine receptor $\mathrm{Ca} 2+$ release channels. Molecular mechanism and isoform selectivity. J Biol Chem 276: 13810-13816.

12. Litman RS, Rosenberg H (2005) Malignant hyperthermia: update on susceptibility testing. JAMA 293: 2918-2924.

13. Gillard EF, Otsu K, Fujii J, Khanna VK, de Leon S, et al. (1991) A substitution of cysteine for arginine 614 in the ryanodine receptor is potentially causative of human malignant hyperthermia. Genomics 11: 751-755.

14. Galli L, Orrico A, Lorenzini S, Censini S, Falciani M, et al. (2006) Frequency and localization of mutations in the 106 exons of the RYR1 gene in 50 individuals with malignant hyperthermia. Hum Mutat 27: 830.

15. Yuge O, Mukaida K (2002) [Malignant hyperthermia]. Nihon Rinsho 60 Supp 1: $635-642$. 